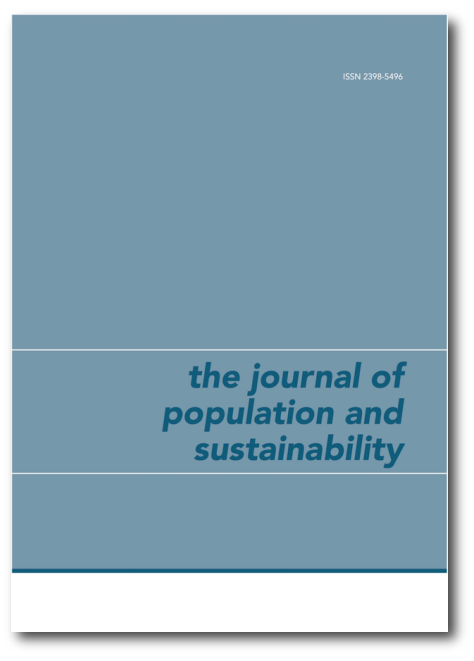

The Journal of Population and Sustainability

ISSN 2398-5496

Article title: We know how many people the earth can support

Author(s): Christopher Tucker

Vol. 5, No. 1, 2020, pp.77-85

doi: 10.3197/jps.2020.5.1.77

Open Access - CC BY 4.0 


\title{
COMMENT
}

\section{We know how many people the earth can support}

\author{
Christopher Tucker ${ }^{1}$
}

Chairman, American Geographical Society

\section{Abstract}

A quarter century after Joel Cohen asked the essential question "How Many People can the Earth Support?", this article offers an answer, based on new science and geographical analysis, and asserts that we have long ago exceeded our planet's long term ecological carrying capacity that optimistically can only support 3 billion modern industrialized humans. While agreeing that strategies based on reducing consumption are sorely needed to live within our planet's carrying capacity, the impending explosion of the global middle class promises to render consumption-only strategies inadequate, in the face of runaway population growth and the accumulation of massive ecological debt. Noting recent studies that project global population to begin to decrease in 2064 after peaking at 9.7B, it is asked why we don't act now to accelerate this already inevitable trend with enhanced investment in women's empowerment, education, and access to family planning technologies. This paper calls for a goal of achieving 1.5 total fertility rate (TFR) by 2030 to bend the global population curve, begin relieving the ecological burden humanity has foisted on our planet, and to decrease human population as we approach 2100 to something closer to the long term ecological carrying capacity of our planet.

1 tucker@americangeo.org 
Keywords: carrying capacity; ecological debt; runaway population growth; women's empowerment.

There is absolutely no doubt that runaway population growth, and our ever growing human footprint have led us to overshoot our planet's long term ecological carrying capacity. Our industrialization of the Earth's surface has systematically deleted ecosystem goods and services that our species, and all other species, rely on. As we add 80 million humans to the planet each year - the equivalent of ten New York Cities - each additional human places even more demand on our planet for resources. All the while, we steadily increase the volume and geographic spread of humanity's persistent and accumulating wastes, further burdening our ever diminishing, and already beleaguered ecological resources. Not only have we exceeded our planet's carrying capacity, but we have managed to incur an ecological debt that will take generations to pay down, if ecological catastrophe does not exact its toll on us first.

Yet, we still tend to do little but admire the global population curve as it progresses ever upwards, occasionally bantering about when it might level off, as though fertility is completely out of our collective power to affect. Before we annihilate the planet from which we evolved, and which fundamentally sustains our species, perhaps we need to change how we approach the subject of population.

\section{The way the world once was}

All of our assumptions about population today are so utterly modern. It is sometimes hard to envision how the world once was. For millennia before the industrial revolution, infant mortality was so high that despite high fertility rates, global population grew at a mere $0.04 \%$ between 10,000 BCE and 1750 AD, hovering barely above replacement level (Volk and Atkinson, 2013). Roughly, this led to a doubling of the world population, or less, every thousand years or so - until the most recent millennium. Before the dawn of our ever-improving agricultural and technical skills, humanity was just able to eke out an existence, holding well below 10 million individuals for hundreds of thousands of years. The combined power of the agricultural, industrial, and scientific revolutions transformed human existence, and led to a steady decrease in infant mortality (and maternal mortality), while decreases in fertility lagged considerably, resulting in a population explosion that we have admired as a centerpiece of modernity - part of what we rightly 
call 'progress'. This progress broke the stability feedback loop, allowing runaway population growth which has decimated the ecosystems that support our species, and undermined our planet's carrying capacity. Of course, we have recognized that in recent decades, the most developed nations have seen their fertility taper off without conscious policy making on the matter, in places where women have been empowered, educated, integrated into the workforce, and achieved access to family planning technologies. This, of course, raises the question why small, educated, and prosperous families are not held up as the hallmark of modernity and progress, instead of runaway population growth.

\section{How many people can the earth support?}

Joel Cohen's 1995 question is the most important question that every citizen and leader should be asking themselves and each other, every single day (Cohen, 1995). Yet, a quarter century has gone by, and we have collectively failed to take it seriously. For a variety of reasons that have been exhaustively covered elsewhere, population growth has not been a mainstream topic of discussion since the 1970s. The doubling of the world population since 1900 was openly discussed as we approached the first Earth Day in 1970 (e.g., 1.6 billion to nearly 3.7 billion). Since this first Earth Day, a half century ago, we have become transfixed by an endless stream of ecological catastrophes and human tragedies, somehow remaining silent on what has become yet another doubling of the world population from nearly 3.7 billion to more than 7.7 billion. We have refused to publicly discuss how these catastrophes and tragedies are in many ways simply symptoms of the runaway population growth that has undermined our planet's long term ecological carrying capacity.

How many people can the Earth support? In my book A Planet of 3 Billion (www.Planet3Billion.com), I offer my analysis, including a review and critique of a variety of approaches to calculating the Earth's carrying capacity (Tucker, 2019a). In that book, I invite everyone to differ with my analysis - if only you will show your data and your math. For the sake of this article, I will forgo a defense of my calculation, which I consider a very optimistic assessment. It is easy not to take issue with less optimistic assessments that come in lower than 3 billion. Higher assessments tend to demonstrate gaping blind spots regarding certain dimensions of humanity's vast and variegated ecological footprint. 
In rough terms (give or take a billion) we actually have a very good sense of how many people the Earth can support. We know that we have overshot our planet's long term ecological carrying capacity. Even if we achieved a carbon-neutral (or even carbon-negative) society, the larger human footprint we would continue to exert on our planet, if population growth continued unchecked, would still have us exceeding our planet's carrying capacity.

\section{Scientists' warning}

The climate change community struggled for decades to gain widespread acceptance of its scientific findings. While fighting tooth and nail to get people to accept that human carbon emissions are driving climate change, this community remained largely silent on the obvious reality that the addition of more humans increases the volume of these carbon emissions. There was a cultural predisposition to blame consumption over population growth for our ever growing carbon footprint - in part to avoid inappropriately blaming poorer nations for a carbon footprint that has been overwhelmingly driven by rich nations. This all changed in November 2019, when 11,000+ scientists signed on to the "Scientists' Warning on Climate Change" in the journal BioScience - and for the first time called for the stabilization and then decrease of human population if we are to avert climate catastrophe - even assuming we were able to materially reduce consumption in the developed world, and stem growing consumption in the developing world as billions race to join the global middle class (Ripple, et.al., 2019). Some climate action advocates will no doubt take a bit of time to incorporate this scientific consensus into their orthodoxy and their calls for action. But, the seal has been broken, and runaway population growth is now a mainstream concern within the climate science, climate action, and climate restoration communities.

Unfortunately, the carbon emissions driving climate change are just one small portion of the larger human footprint. Our human footprint is much larger perhaps 10 times larger. As I like to say, "What if climate change were twice as bad as the worst projections, and still only 1/10th of the problem that humanity has foisted on our planet?" (Tucker, 2019b). This makes the urgency of ending runaway population growth many times more urgent than that communicated in the 'Scientists Warning'. 


\section{Bending the global population curve}

As we quickly approach 8 billion, adding $80+$ million additional souls (again, the equivalent of $10 \mathrm{New}$ York Cities) to our planet each year, so many are confused by basic statistics. Whether it is journalists or their editors, the rampant confusion over a decline in the rate of population growth versus a decline in population continues to muddy these issues in the popular mind. When icons such as Elon Musk and Jack Ma take the world stage and warn of population collapse, while we are actually facing runaway population growth, the average citizen cannot be expected to keep things straight (Clifford, 2019).

While the global Total Fertility Rate (TFR) does indeed continue to decline little by little, ${ }^{2}$ even modest percentages of annual growth atop the existing enormous global population base means massive increases in total numbers, and massive increases in the crushing weight of humanity's ecological footprint. TFR will need to drop from the existing (2020) TFR of 2.448 (Macrotrends, 2020) to a replacement level fertility of 2.1 TFR before global population stops growing.

A recent (July 2019) Lancet article projects that we will reach this TFR of 2.1 by 2064, with global population peaking at 9.7 billion (Vollset, 2020). While somewhat controversial, this article was novel in how it broke down the factors driving population growth. This study team determined that improvements in access to modern contraception and the education of girls and women have progressed, in effect, ahead of schedule, leading fertility to decline more quickly than previously assumed. Their model has population declining to 8.8 billion by 2100 - some 2 billion lower than some of the UN Population Division's estimates.

When interviewed regarding this Lancet article, the head of the UN Population Division, John Wilmoth, characterized the bending of the global population curve as a 'problem', and surmised that it is a problem that nations' leaders will intervene to avert (Gladstone, 2020). It appears that the United Nations community has not yet made a connection between our failure to meet UN Sustainable Development Goals (SDGs) and runaway population growth. Or they, too, have been bamboozled by the cult of perpetual growth.

2 The fertility rate for World in 2019 was 2.458 births per woman, a $0.41 \%$ decline from 2018 (Macrotrends, 2020). 
Interestingly, there has been no discussion about how this already inevitable bending of the global population curve might be accelerated. If it can happen by 2064, why not sooner? The Lancet analysis clearly shows how access to modern contraception and the education of girls and women can drive a decline in fertility, to below replacement level. Thus, it provides a clear roadmap to how this inevitable trend (e.g., the bending of the global population curve) might be accelerated. How much investment in access to modern contraception and the education of girls and women would be required (and in which geographies) to accelerate this inevitable trend? However, this was not the research question driving the Lancet article. Perhaps their follow up work will help answer this question.

\section{5 by 2030}

Of course, we are left to ask ourselves, if this curve is actually something of our own making, and not some inexorable process handed down by the gods, what should our collective goal be? If indeed, our planet's carrying capacity can support a mere 3 billion modern industrialized humans, as billions are now racing to join the global middle class, then what TFR could get us to that lower, more sustainable population plateau?

It is important to note how small changes in complex systems can lead to profound change, very quickly. And, given the urgency we face with climate change, and the threshold of $1.5 \mathrm{C}$ temperature rise that climate scientists and biodiversity experts have settled on as a line that should not be crossed, many have concluded that 2030 is the time horizon by which carbon emissions must end. Flattening the global population curve would not end carbon emissions. However, bringing the population curve below replacement level on the way to 2030 and beyond would certainly help alleviate the carbon burden on our planet, along with the 9 other forms of human footprint currently undermining our planet's ecological carrying capacity.

Not only could we accelerate the bending of the global population curve now, and begin alleviating the population pressure on our planet on or before 2030, but bringing the global TFR down to 1.5 would set us on a course to achieve to a global population of around 3 billion much sooner than current projections anticipate. 
As such, we should ask ourselves, what would it take to bring the global TFR down to 1.5 by 2030 ? In truth, this is not that big a change. And again, it would simply be the acceleration of an inevitable trend that we already predict for later in the century. People need to remember that in many urban areas around the world, a TFR of 1.5 or lower is the norm. Further, all predictions indicate that a vast majority of humanity will move into urban environments over the coming decades. Investing further in the humane, ethical, and empowering strategies outlined by the Lancet report could bend the global population curve by 2030 , bringing global TFR to 1.5, and perhaps even help us avert a temperature increase of $1.5 \mathrm{C}$ or more. Small, educated, prosperous families living in urban communities would become the species wide norm.

\section{Pick your challenge}

When faced with a challenging proposal, it is easy to throw up one's hands, and be overwhelmed by the difficulty of the task. However, we are already challenged by calls for epic, planetary-scale policy initiatives intended to bend the curve of carbon in our atmosphere and our oceans - which runaway population growth only serves to exacerbate. Similar proposals seek to bend the curves driving loss in natural habitat and biodiversity, fresh water resources, and the diminishment of so many other elements of our world ecology. Of course, runaway population growth is at the heart of all of these exasperating trends. In a very real sense, bending the global population curve makes the realization of so many of our goals so much more plausible.

We could educate more women more quickly. That is called education policy. We could integrate more women into the workforce more quickly. That is called labor policy, (micro-) finance policy, and economic policy more generally. We could empower more women more quickly, by investing in access to family planning technologies, norm shifting media interventions, and civil society initiatives. We could encourage small, educated and prosperous families. None of these policies are controversial. Many of these goals are already called out in our Sustainable Development Goals. But the order and sequencing with which we undertake these policies matters. It seems clear that an 18th SDG should be added, as a capstone, that calls for an end to the runaway population growth that is undermining our accomplishment of the other 17 SDGs.

Perhaps the 18th SDG should call for 1.5 TFR by 2030. 


\section{Empowering future generations to save our planet and our species}

Without malice of forethought, we have exceeded our planet's carrying capacity. In doing this, we have put future generations in the crosshairs of ecological catastrophe and human tragedy. But, we could very easily achieve a more sustainably and equitably prosperous global society that enables everyone to live the good life within our planetary boundaries. We could even do this very quickly, through humane, ethical, and just policies. We must simply stop acting as if population growth is some unfathomable process that humanity could never craft to its own advantage, and to the benefit of the planet that gives us life.

It is entirely feasible to achieve a more just and sustainable planet - one where small, educated and prosperous families think deliberately about their impact on each other and the ecosystems that give them life. We need not force future generations to embrace the fear and uncertainty posed by the ecological calamity that awaits if we refuse to change. We need only build bridges to the rest of our brethren, across the globe, to accelerate already inevitable trends, and bend the global population curve by collectively investing in humane, ethical, and empowering strategies that will leave our world and our society better off than when we entered it.

\section{References}

Clifford, C., 2019. Elon Musk and Jack Ma agree: the biggest problem the world will face is population collapse. CNBC Make It. [online] August 30. Available at: https://www.cnbc.com/2019/08/30/elon-musk-jack-ma-biggest-problem-worldwill-face-is-population-drop.html [Accessed 1 November 2020].

Cohen, J.E., 1995. How many people can The Earth support? New York: W.W. Norton \& Company.

Gladstone, R., 2020. World population could peak decades ahead of U.N. forecast, study asserts. New York Times. [online] July 14. Available at: https:// www.nytimes.com/2020/07/14/world/americas/global-population-trends.html [Accessed 17 November 2020].

Macrotrends, 2020. World fertility rate 1950-2020. [online] Available at: https://www.macrotrends.net/countries/WLD/world/fertility-rate [Accessed 17 November 2020]. 
Ripple, W.J., et. al., 2019. World scientists' warning of a climate emergency. BioScience, 70(1), pp.8-12.

Tucker, C.K., 2019a. A planet of 3 billion. Washington, DC: Atlas Observatory Press. Tucker, C.K., 2019b. A planet of 3 billion by Christopher Tucker - book extract. World Economic Forum. [online] Available at: https://www.weforum.org/ agenda/2019/09/christopher-tucker-planet-of-3-billion-book-extract-climatechange [Accessed 1 November 2020].

Volk, A.A. and Atkinson J.A., 2013. Infant and child death in the human environment of evolutionary adaptation. Evolution and Human Behavior, 34(3), pp.182-192. https://doi.org/10.1016/j.evolhumbehav.2012.11.007.

Vollset, S.E., Goren, E., Yuan, C.-W., Cao, J., et al., 2020. Fertility, mortality, migration, and population scenarios for 195 countries and territories from 2017 to 2100: a forecasting analysis for the Global Burden of Disease Study. The Lancet, 396(10258), pp.1285-1306. https://doi.org/10.1016/S0140-6736(20)30677-2. 